\title{
Study on the Cultivation of New Agricultural Business Entities in Chongqing
}

\author{
Xin Wei \\ Yangtze Normal University \\ Chongqing, China
}

\author{
Yi Li \\ Yangtze Normal University \\ Chongqing, China
}

\begin{abstract}
Against the background of separation of three powers, the only way for the Rural Revitalization Strategy and the construction of modern agriculture is to cultivate new agricultural business entities. At present, the central and local governments have carried out the work of cultivating new agricultural management entities, and there are still many problems in the initial stage of cultivation. This paper chooses Chongqing as the research object, through on-the-spot investigation, interviews and literature review, to understand the current situation and existing problems of cultivating new agricultural management subjects in Chongqing. The main problems are financial funds, supporting policies, government positioning, teaching staff, and cultivation model, and the corresponding solutions are put forward.
\end{abstract}

Keywords-new agricultural business entities; cultivation; Chongqing; local government

\section{INTRODUCTION}

The purpose of the three-power separation reform is to invigorate the whole agricultural management pattern by adjusting and transforming the land ownership relationship. And the new agricultural business entity is the center of the transform of land ownership relationship. Therefore, the reform of the three rights separation requires the cultivation of a new type of agricultural management entities which is compatible with this new-type tenure relationship. The road of rural revitalization under socialism with Chinese characteristics rely on the lead of an agricultural management organization which have a relatively large scale of operation, better material equipment conditions, management capacity, and rather high labor production, resource utilization and land yield, with commercialized production as the main goal, that is, the new agricultural business entity. Training and educating the new type of agricultural management subject, developing the moderate scale management in various forms, perfecting the agricultural socialized service system, to realize the organic connection between small farmers and the development of modern agriculture, it is the realistic choice to realize agricultural modernization. Additionally, the cultivation of the new entity of agricultural management is helpful to innovate agricultural environmental management, play an exemplary role in the prevention and control of agricultural surface source pollution, and promote the application of green and efficient technology in a wider range.

\section{The BASIC INFORMATION OF CULTIVATING NEW AGRICULTURAL BUSINESS ENTITY IN CHONGQING}

\section{A. Basice Information of the Entities of Agricultural Business}

According to survey data on agricultural business entity and agricultural producer and operator from the third national agricultural census of Chongqing, there were 105,400 agricultural management units in the city in 2016 At the end of 2016, the total number of farmers' cooperatives registered in the industrial and commercial sectors was 29,500 , of which 16,700 farmers' cooperatives major in agricultural production operations or services. There are $5,826,200$ agricultural management households, of which 2,850 are large-scale agricultural management households. There are 7,599,300 agricultural production and operation personnel in the city of Chongqing. (As shown in "Table I")

TABle I. The Structure of Agricultural Production AND OPERATION PERSONNEL

\begin{tabular}{|c|c|c|c|}
\hline $\begin{array}{c}\text { Agricultural } \\
\text { production and } \\
\text { operation } \\
\text { personnel }^{\text {b }}\end{array}$ & $\begin{array}{c}\text { Total } \\
\text { number }\end{array}$ & $\begin{array}{c}\text { Scale } \\
\text { Agricultural } \\
\text { households }^{c}\end{array}$ & $\begin{array}{c}\text { Agricultural } \\
\text { business } \\
\text { units }^{d}\end{array}$ \\
\hline Total number & $7,599,300$ & 123800 & 359200 \\
\hline \multicolumn{4}{|l|}{ Gender } \\
\hline Male & $51.5 \%$ & $50.8 \%$ & $54.2 \%$ \\
\hline Female & $48.5 \%$ & $49.2 \%$ & $45.8 \%$ \\
\hline \multicolumn{4}{|l|}{ Age } \\
\hline Below 35 years-old & $9.1 \%$ & $13.9 \%$ & $13.3 \%$ \\
\hline 35-45 years-old & $45.9 \%$ & $60.2 \%$ & $60.4 \%$ \\
\hline Over 45 years-old & $45.0 \%$ & $25.9 \%$ & $26.3 \%$ \\
\hline \multicolumn{4}{|l|}{ Education } \\
\hline Non-educated & $6.6 \%$ & $3.8 \%$ & $2.9 \%$ \\
\hline Primary school & $52.5 \%$ & $41.0 \%$ & $30.2 \%$ \\
\hline Junior school & $35.5 \%$ & $44.9 \%$ & $45.0 \%$ \\
\hline
\end{tabular}




\begin{tabular}{|c|l|l|l|}
\hline $\begin{array}{c}\text { Agricultural } \\
\text { production and } \\
\text { operation } \\
\text { personnel }\end{array}$ & $\begin{array}{c}\text { Total } \\
\text { number }\end{array}$ & $\begin{array}{c}\text { Scale } \\
\text { Agricultural } \\
\text { households }\end{array}$ & $\begin{array}{c}\text { Agricultural } \\
\text { business } \\
\text { units }\end{array}$ \\
\hline $\begin{array}{c}\text { d } \\
\text { Senior } \\
\text { school/Secondary } \\
\text { vocational School }\end{array}$ & $4.5 \%$ & $8.5 \%$ & $14.6 \%$ \\
\hline College or above & $0.9 \%$ & $1.7 \%$ & $7.3 \%$ \\
\hline
\end{tabular}
days in agricultural operators or agricultural operation units.

c. "Scale agricultural households" refer to agricultural management household with large scale of agricultural operation and mainly commercialized management.

d. "Agricultural business units" refer to legal persons and unregistered units engaged in agricultural "production and operation activities within the territory of the People's Republic of China, and pricultural industrial activities units in legal persons or unregistered units that do not manly engage in agricultural production and opert

\section{B. Cultivating New Agricultural Management Entity}

The Fifth Plenary Session of the Eighteenth Central Committee of the CPC, the Outline of the 13th Five-Year Plan, the Report of the 19th National Congress, the Central Rural Work Conference in 2018, and the Report of the Government of Chongqing in 2017 all put forward constructing the policy system of cultivating new agricultural management entity. Document basis: "Opinions on Accelerating the Construction of Policy System and Cultivating New-type Agricultural Business Entity " issued by general office of the State Council on May 31th", "Implementing Opinions of the General Office of Chongqing Municipal People's Government on Accelerating the Integration and Development of Rural First, Second and Third Industries " Yu (2016) No. 247. Leadership Speech: On July 27, 2015, Zuxiang Xia, Director of the Municipal Agricultural Commission, delivered "the Report of the Chongqing Municipal People's Government on the Construction of a New Agricultural Management System" at the 19th meeting of the Standing Committee of the Fourth Municipal People's Congress.

By 2017, Chongqing has focused on training a new type of professional peasant team with high comprehensive quality, strong ability of production and operation, and obviously main role. 18714 new professional peasants have been cultivated throughout the year. Among them, 5000 pioneers of new agricultural management subjects, 300 modern young farmers, 600 rural practical talent are included. 53 entrepreneurship Incubation bases for young farmers are created throughout the year. While 3,626 leading enterprises, 30,700 cooperatives, 19,000 family farms, 145,000 households of large breeder, 9,200 socialized service organization were developed. At the same time, acres moderate-scale operating area were up to 12.55 million, moderate-scale management accounting for $42.1 \%$ while cultivation mechanization accounting for $45 \%$. The area of land circulation was 1946.2 acres and turnover rate was $42.9 \%$.

\section{The Problem of Cultivating NeW AGRICULTURAL BUSINESS ENTITY}

The majority of cooperatives, large households, and family farm are not strong, emphasize production rather than market, and hence have poor economic profits. There still exist problem that the supporting policies are incompatible, the docking of financing supply and demand is not smooth, the transfer of land is difficult, and social service level is low. Except that, the "1.3" snow disaster caused collapse of most facilities and greenhouses in Yunyang County, Fengjie County and Wuxi County, losing more than 20 million yuan. Most facilities shed collapse, loss of more than 20 million yuan. The new management subject needs to be nurtured and strengthened urgently in order to promote the process of rural revitalization and agricultural modernization. Given that it is urgent to cultivate and strengthen the new-type business entities in order to promote the process of Rural Revitalization and agricultural modernization. However, the following problems still exist in the entities of new agricultural management in Chongqing.

\section{A. Unclear Government Positioning, Absence of Some Functions Malposition and Offside}

The city has formed an educational model in which agricultural colleges and universities, secondary and higher agricultural vocational colleges, agricultural extension service institutions, agricultural scientific research institutes, agricultural enterprises and farmers' cooperatives participate extensively. Municipal government, as one of the main bodies of cultivating new agricultural management subjects, plays an unobtrusive role in cultivating new agricultural management subjects, as well as its responsibility boundary is blurred. There is a lack of comprehensive and unified planning and deployment in the formulation of the cultivation scheme for new agricultural management subjects, which is usually a framework arrangement, not scientific and reasonable. Local government departments are sometimes passive and coping in the implementation of cultivation of new-type professional farmers. Chongqing has not yet set up a unified special regulatory agency or organization for the cultivation of new agricultural operators. The municipal agricultural administrative department (Municipal Agricultural Commission) is mainly responsible for the cultivation of new agricultural operators while the municipal education administrative department (Municipal Education Commission) and its agricultural colleges and universities and comprehensive colleges which set up agriculture-related majors are responsible for the vocational education of new agricultural operators. The roles of the two departments in the cultivation have not been fully clarified, and thus the absence, malposition and offside of responsibilities occur now and then. Moreover, the administrative departments such as finance, human resources and social security are not fully clear about their responsibilities for cultivation. However, the government-led cultivation resources have not been effectively integrated and allocated. Moreover, the relevant government departments often lack communication and connection with other cultivators in the specific 
implementation of agricultural training projects, and act as they please; they lack long-term and stable plan in supporting leading agricultural enterprises and rural intermediary organizations.

Moreover, when it comes to rural areas, leading cadres lack awareness and strong sense of leadership on the cultivation of new-type professional farmers at the grassroots level. Leading cadres at the grass-roots level do not realize the social benefits of cultivation of new agricultural business entity for agricultural development and rural construction, easily lead to farmers' shortage of awareness of cultivation. Particularly, the lack of initiative to take the lead in nurturing can easily result in the lack of information on the cultivation of superiors and subordinates.

\section{B. Inadequate Policy System, Absence of Supporting and Enabling Policies}

In recent years, the state and Chongqing municipal level have issued a number of policies to foster the development and growth of new agricultural operators. But from the present point of view, there are still the following four aspects of the problem: firstly, there is disconnect in policy. Many policies to cultivate and support the development and growth of new agricultural management subjects are issued through the orders of higher departments, and it is inevitable that there is a lack of integration and cohesion after delivery to the counties. At the same time, some support policies are not flexible enough to match the needs of actual work; secondly, the efficiency of policy implementation is not yet high. Many policies experience too much intermediate level and links from the upper to the bottom, resulting in higher cost of policy implementation. Therefore, polices have obvious time lag and low efficiency; thirdly, complementary polices of cultivation are not perfect. The existing agricultural subsidy policy is mainly for planting industry, seldom for large-scale operators, such as the farming households and agricultural machinery. There is as well a lack of corresponding subsidies for the inflow of new subjects into land and the development of quality and safety certification. Lastly, the district and county level are too weak to supporting.

For example, "Dian Liang Feng Zhong" four counties are not only all the large agricultural counties, but also the large fiscal deficit counties; the cultivation work is often in the "powerless" embarrassing situation [1].

\section{Insufficient Cultivation Funds and Investment Financing Difficulties}

Different with the general technical training, the train of new agricultural management subject is a life-long education process with long-term, systematic and professional characteristics. Therefore, more funds are needed for the cultivation of new agricultural management entities.

Through the analysis of the fiscal expending in the cultivation of new-type professional farmers in Chongqing from 2013 to 2016, Yang (2017) found that the funds for the cultivation were far from meeting the needs of the cultivation of new-type professional farmers [2]. The actual investment from Chongqing municipal government is seriously inadequate, and the supporting funds of districts and counties are less or completely missing. For example, the total amount of cultivation funds in Chongqing in 2015 was 82 million, while the total amount of cultivation funds in 2016 was 70 million, 50 million of which were matched by the central finance while only 20 million were invested by the Chongqing Municipal Government. Obviously, the cultivation funds were insufficient. Nevertheless, only the funds for the cultivation of productive professional farmers and young farmers in the counties and districts have reached 70 million by 2016. (As shown in "Table II") The training and educating of other types of new agricultural business entities were neglected due to the lack of funds. And almost the funds the relevant cultivation projects obtained come from the central and municipal financial allocation, while other channels are very few. The main reasons are that local governments, especially the district and county governments who are responsible for the specific implementation, pay little attention to the projects and lack of scientific budget, resulting in inadequate financial investment.

TABLE II. FUNDS OF CHONGQING MUNICIPAL GOVERNMENT FOR CULTIVATING NEW PROFESSIONAL FARMERS FROM 2013 TO 2016

\begin{tabular}{|c|l|l|l|l|}
\hline \multirow{2}{*}{$\begin{array}{c}\text { Funds } \\
\text { (million } \\
\text { yuan) }\end{array}$} & 2013 & 2014 & 2015 & 2016 \\
\cline { 3 - 5 } $\begin{array}{c}\text { Central } \\
\text { finance }\end{array}$ & 23.96 & 50 & 62 & 50 \\
\cline { 1 - 4 } $\begin{array}{c}\text { Local } \\
\text { finance }\end{array}$ & 20 & 20 & 20 \\
\cline { 3 - 5 } & 20 & \multicolumn{5}{|c|}{ a. Tided by Yang (2017) } \\
\hline \multicolumn{5}{|c|}{}
\end{tabular}

\section{Unreasonable Distribution of Educational Resources and Lack of Cultivation Teachers}

Modern agriculture has a high demand for the quality of management entities. In the early stage of the development of new-types agricultural business entities, some are traditional farmers with lower cultural level, and others are laymen in agriculture, lacking understanding of the complexity and arduousness of developing agriculture. Therefore, it is necessary to strengthen targeted training and cultivate a new type of management subject who knows technology and is good at management. The resources of farmers' vocational education in Chongqing are mainly concentrated in the main cities and main districts, and the resources of farmers' vocational education at county level and below are relatively short. Comprehensive colleges, research institutes and agricultural colleges with agriculturerelated departments and specialties are mainly concentrated in the main urban area. Although Chongqing agriculture TV broadcast school has four-level systems, the high-quality educational resources are also concentrated in the municipal agricultural TV broadcast school. It results from complex factors, not only the historical factor, but also the realistic factor. Both the government reason and the market reason are included. Moreover, the increasing orientation of market economy contributes a general tendency towards the comprehensive development of agricultural-integrated colleges in the city. Agricultural specialty has partly been weakened, the subject system is divided, and the function of 
agricultural education and training has been weakened. At the same time, the number of tertiary agricultural colleges and universities has decreased, and a large proportion of vocational and technical schools have entered the road of agriculturalization.

\section{E. Lack of Effective Cultivation Mode and Curing of Cultivation Method}

Chongqing Agricultural and Broadcasting University relies on its three-level system of "City (Agricultural and Broadcasting University) - District (Branch) and Township (Workstation)" to establish the main network of cultivating new-type professional farmers and become the main position of cultivating new-type business entities of Chongqing Municipal Government. It's said that the mode of agricultural and broadcasting schools is still the main way to cultivate new professional farmers, and the majority of them are curriculum mode (classroom teaching), theory (abstract) teaching, and most of them are large class teaching, followed by field classroom teaching. Although in recent years, Agricultural and Broadcasting University have been trying to innovate new ways of cultivating professional farmers, including field classes, sending education to the countryside, $" 2+2 "$ tutorial system (cultivation of the leader of the new agricultural business entities), outward bound training, field exchanges, base training, follow-up and effectiveness). Due to the influence of the traditional system, the cultivation mode is relatively solidified, and the pace of innovation of cultivation mode is still slow, which cannot satisfy the demand of cultivation under the trend of modern agriculture. In view of the actual situation of agriculture in Chongqing, it is not easy to form an efficient and classical cultivation model. The cultivation is still in the early stage of development in practical experience, lack of publicity, and their cultivation methods, intellectual support and follow-up training services are not fully matched. Moreover, the unified network (website) for the cultivation of new-type management subjects has not yet been established by Chongqing municipal government. Therefore, the cultivation of new-type professional farmers lacks the support of network technology and data, and there is still a gap between the targeted and refined cultivation. It is found through interviews that effective ways of cultivation are insufficient and the overall effect of cultivation is not obvious, contributing to the limitations of funds, technology and teaching conditions, especially the imbalance of teaching conditions. Lacking effective cultivation methods is still the shortcoming of the district and county governments to cultivate new types of professional farmers.

\section{Cultivation COUnTERMEASURES}

\section{A. Establishing and Perfecting the Leading Management System of Farmers' Training in China}

The government should attach great importance to the establishment of a leading group for farmers' training and educating led by the agricultural sector and participated by the Ministry of Education and the Ministry of Science and Technology and so on, giving full play to the role of the leading group for " the integration of agriculture, science and education", with full-time staff responsible for dedicated work, with clear powers, macro-decision-making, overall coordination and supervision and inspection. On this basis, efforts should be made to establish and improve the management system and operation mechanism of farmer training, clarify the responsibilities and tasks of the competent departments and related departments, strengthen coordination and cooperation, supervision and promotion among departments, so as to completely change the current situation of decentralized management and shirk responsibility for management.

\section{B. Improving Policy Support System}

On the basis of the actual situation in Chongqing, support policies are formulated according to functional areas, industries, levels and classifications, focusing on the 11 leading industries and seven characteristic industrial chains in Chongqing. At the same time, it is inclined to the new agricultural management subject with science and technology, management ability and production and operation type, and is constantly improving, striving to form a scientific and rational policy system for cultivating and supporting the new agricultural management subject.

\section{Increasing the Investment in the Cultivation of New Agricultural Business Entities}

The experience of western developed countries states that the governments are suggested to strongly support the cultivation of new agricultural entities, and guarantee the investment of funds by legal means. According to the theory of public goods, the cultivation of new agricultural management subjects is both public and private. Therefore, according to the national policy and the actual situation of locality (Chongqing), improving the city's modern agricultural investment and financing system is an important measure to effectively meet the needs of cultivation funds for new agricultural operators. First of all, it is necessary to establish a diversified input system, in which government financial allocation as the main, corporate social sponsorship as a supplement, new agricultural management entities cultivated is properly burdened. Local governments should establish a stable growth mechanism of financial input and increase investment in the cultivation of new professional farmers. The investment in agricultural projects should increase with the economic growth. Local (Chongqing) finance should adjust the structure of fiscal expenditure according to policies, increase investment in agriculture, and form a stable growth mechanism of agricultural investment. Second, the government has given certain credit preferential policies. Actively encourage training institutions to expand the scale, improve equipment, and improve the strength of teachers. Only in this way can the development of cultivation of new agricultural operators not be "water without source, wood without root". Third, it is important to integrate and bundle the use of agricultural-related funds in the form of agricultural projects, strengthen supervision and auditing, so as to improve the efficiency of the use of funds. At the same time, inputting funds to establish a new type of municipal professional farmer venture capital, for new type of professional farmers venture discount, etc. 


\section{Strengthening the Construction of Teachers}

First, it is needed to integrate teachers, taking regional Agricultural and Broadcasting Schools, regional vocational education centers and district administrative schools as the carriers, to employ experts and professors from scientific research institutes such as Southwest University and Municipal Academy of Agricultural Sciences to teach, to carry out projects such as green, high quality and efficient creation, organic fertilizer substitution for chemical fertilizer, whole process green prevention and control pilot projects and so on. So that, it is able to grasp the technical essentials, strengthen demonstration guidance, and improve the overall level of scientific farming. Second is to create a good environment for agricultural entrepreneurship. Attract scientific researchers, agricultural technicians and college graduates to take part-time jobs in the new agricultural business entities, to carry out technical guidance services, improve the incentive mechanism of intellectual property rights and participation in dividend distribution, improve the structure of agricultural technicians, and mobilize various social forces to participate in the practice of "rural revitalization strategy".

\section{E. Innovating the Cultivation Model}

Expand the "Agricultural and Broadcasting Schools" model. As the main position and main force of cultivating new agricultural management subjects, the innovation of its cultivation mode is of great significance to the cultivation of new agricultural management subjects. On the basis of consolidating the original "four-level" teaching methods, the government encourages the Agricultural and Broadcasting Schools to keep pace with the times and continuously innovate the cultivation mode and enrich the cultivation methods. For example, establishing "county-town-village" three-level training network platform, using new media technology, using short video, "020" Wechat (online to offline) service, which uses voice, text, pictures, video and other ways to answer questions.

\section{CONCLUSION}

It is the only way to revitalize the countryside and modernize the agriculture to cultivate the new type of agricultural management subject, and the local government (Chongqing) has more power and responsibility in the cultivation. Based on the actual situation of agriculture in Chongqing, and on the basis of summing up the cultivation experience of various districts and counties, this paper puts forward the Countermeasures for local (Chongqing) government to cultivate local (Chongqing) government to cultivate new type of professional farmers. These countermeasures contain establishing and perfecting the leading management system of farmers ' training, improving policy support system, increasing the investment in the cultivation of new agricultural business entities, strengthening the construction of teachers and innovating the cultivation model.

\section{REFERENCES}

[1] F. Zhou, and B. Chen, Suggestions on the cultivation of new agricultural operators - Take Chongqing "Dian-Liang-Feng-Zhong" plate as an example [J]. Labor Security World, 2016 (14): 51-53.

[2] Y. Yang, Problems and Countermeasures of local government in cultivating new-type professional farmers [D]. Party School of Chongqing Municipal Committee of the Communist Party of China, 2017.

[3] S. Tan, et al. Exploration on the cultivation and development of new agricultural business entities in Kaizhou District [J]. Southern Agriculture, 2018, 12 (13): 46-48

[4] X. Zeng, and W. Peng, Investigation and Thought on Cultivating New Type Agricultural Operating Subjects — Taking Jiajiang County of Leshan City as an Example [J]. Journal of Party School of Leshan Municipal Committee of the Communist Party of China, 2016, 18 (04): 84-85.

[5] L. Lu, C. Yao, and L. Cao, Modernization of People: Research on the Cultivation of New Farmers by New Media [J]. China Agricultural Education, 2016 (02): 37-42+73.

[6] K. Huang, Innovation Research on Financial Service System of New Agricultural Operators [D]. Northeast Agricultural University, 2017.

[7] G, Zuo, Moderately develop family farms and speed up the cultivation of new agricultural management subjects - Take Banan District of Chongqing as an example [J]. Chongqing Administration (Public Forum), 2015, 16 (04): 41-42

[8] M. Zeng, Strategic Research on New Vocational Farmer Training under the Strategy of Rural Revitalization - Take Zengcheng District of Guangzhou as an example [J]. Special Economic Zone, 2019 (05): 133-135.

[9] X. Chen, Investigation and Thought on Cultivating New Type Agricultural Operators in Rongchang District of Chongqing [J]. Chongqing Administration (Public Forum), 2018, 19 (05): 63-65. 